\title{
Numerical Investigations of Injection Timing Effects on a GDI Engine Performance: Part B, In-Cylinder Emission Formation and Oxidation Process
}

\section{OPEN ACCESS}

Edited by:

Jun Li,

Guangzhou Institute of Energy Conversion (CAS), China

Reviewed by:

Haifeng Liu,

Tianjin University, China

Saravanan Balusamy,

Indian Institute of Technology

Hyderabad, India

${ }^{*}$ Correspondence:

Jiahong Fu

fujh@zucc.edu.cn

Zhentao Liu

liuzt@zju.edu.cn

Specialty section:

This article was submitted to Advanced Clean Fuel Technologies,

a section of the journal Frontiers in Energy Research

Received: 27 November 2021 Accepted: 13 January 2022

Published: 25 February 2022

Citation:

Zhang Y, Yang R, Yan Y, Li R, Fu J and Liu $Z$ (2022) Numerical Investigations of Injection Timing Effects on a GDI Engine Performance: Part B, InCylinder Emission Formation and Oxidation Process.

Front. Energy Res. 10:823386. doi: 10.3389/fenrg.2022.823386

\begin{abstract}
Yu Zhang ${ }^{1}$, Ruomiao Yang ${ }^{2}$, Yuchao Yan ${ }^{2}$, Ruijie $\mathrm{Li}^{3}$, Jiahong $\mathrm{Fu}^{1 *}$ and Zhentao $\mathrm{Liu}^{2 *}$
${ }^{1}$ Department of Mechanical Engineering, Zhejiang University City College, Hangzhou, China, ${ }^{2}$ Power Machinery and Vehicular Engineering Institute, Zhejiang University, Hangzhou, China, ${ }^{3} T e c h n i c a l$ Institute of Physics and Chemistry, Chinese Academy of Sciences, Beijing, China
\end{abstract}

The emphasis on environmental protection and energy security has promoted automobile engine technology toward low emission and economy. While the traditional port fuel injection engine can hardly meet the latest regulations and requirements, the gasoline direct injection (GDI) engine becomes a hot research topic because of its potential to reduce fuel consumption and emissions. Since injection timing has a determining effect on overall engine performance, this paper aimed to investigate the injection timing effects on mixture formation and emissions. A validated three-dimensional numerical simulation model of a 4-stroke GDI engine combustion chamber was adopted. In a previous work (Part A), the in-cylinder combustion process has been discussed. In this study, the simulation results demonstrate that with the injection timing advancing, the fuel-gas mixture was more uniformly distributed and combusted more completely; the CO, UHC, and soot had decreased sharply by $80.6,99.2$, and $97.5 \%$; the NOx emission increased by $151.7 \%$. The optimized injection timing for this case was $300 \mathrm{CA}$ BTDC. Moreover, this paper studied the in-cylinder views of injection timing effects on mixture formation and emission, providing reference to optimize injection of GDI engine.

Keywords: GDI engine, injection timing, emission, CFD, oxidation

\section{INTRODUCTION}

The increasing prominent energy shortage and emission pollution have put forward severe challenges to the automobile power system (Gasbarro et al., 2019; Yang et al., 2021). Therefore, reducing emissions and improving the efficiency of internal combustion engines (ICEs) have become the main targets of research on vehicle engines (Ambrogi et al., 2019; Duronio et al., 2020). Although the electric vehicle is in the ascendant, short driving range (Liu A. et al., 2021; Xu et al., 2021), high cost (Lin and Li, 2019; Wang and Shen, 2021a), and battery safety are the main disadvantages that cannot be ignored (Zhao et al., 1999; Wang and Shen, 2020). Therefore, the ICE will still be the main

Abbreviations: 3D, three-dimensional; AFR, air-fuel ratio; ATDC, after top dead center; BTDC, before top dead center; CAD, crank angle degree; CFD, computational fluid dynamics; CO, carbon monoxide; DMF, dimethylfuran; DPF, diesel particulate filter; GDI, gasoline direct injection; ICE, internal combustion engine; IT, injection timing; NOx, nitrogen oxide; PFI, port fuel injection; RON, research octane number; SI, spark-ignition engine; TWC, three-way catalyst; UHC, unburned hydrocarbon. 

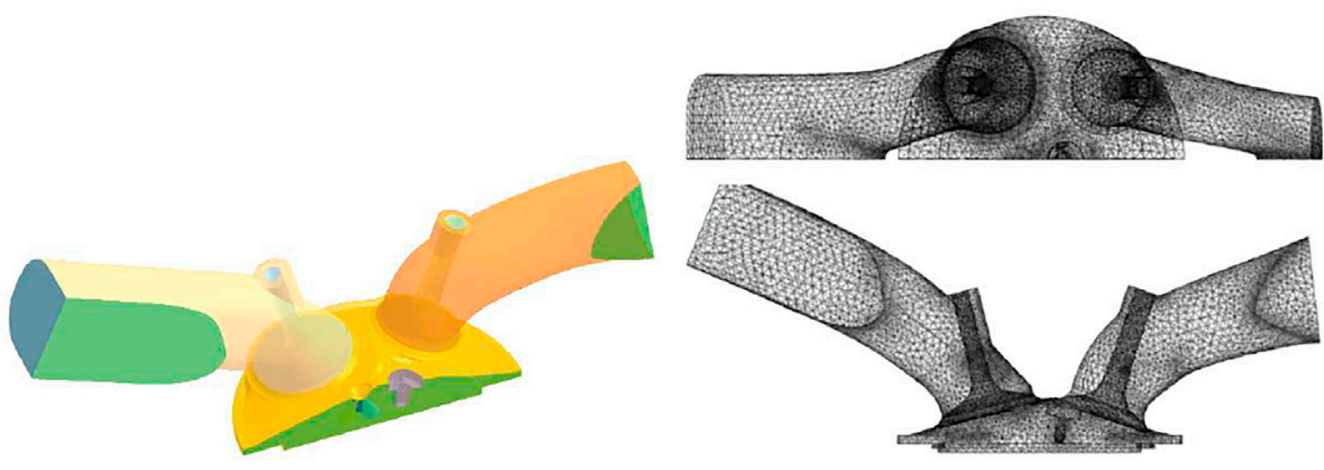

FIGURE 1 | Engine model geometry and mesh.

power resource of the vehicle in the foreseeable future (Heywood, 2018; Li et al., 2019). Also, many researchers have studied combustion models (Keskinen et al., 2016; Shi et al., 2019), heat transfer (Hongliang et al., 2016; Xu et al., 2020a), injection strategies (Shi et al., 2018; Chai et al., 2021), and emissions (Liu and Rigopoulos, 2019; Lin et al., 2021) related to internal combustion engines. While the traditional port fuel injection (PFI) engine has difficulty meeting the requirement of environment protection and economic efficiency, attention is attracted to the gasoline direct injection (GDI) engine (Wang and Shuai, 2011; Liu and Wang, 2022). Also, for GDI engines under partial load conditions, stratified combustion can be achieved through a reasonable injection strategy (Wang and Shen, 2021b; Yu et al., 2022), while under full load conditions, a homogeneous mixture of premixed combustion can be achieved through earlier injection (Yu et al., 2017; Liu et al., 2020). Considering the significant improvement in thermal efficiency and reducing fuel cost, the GDI engine has become a hot research topic (Leduc et al., 2003; Han et al., 2020).

Thanks to the development of accurately controlled injectors like solenoid-actuated and piezo-actuated injectors (Anbari Attar et al., 2014; Lin et al., 2019), the GDI technology can precisely control the injection timing (IT) and quantity, and allows more choice on injection strategies (Lake et al., 2004; Zheng et al., 2021). More importantly, the GDI technology shows great potential in cooperation with engine downsizing, turbocharging, and other technologies (Leduc et al., 2003; Wang and Shen, 2021c). The downsized engine is well known for less fuel consumption in a

TABLE 1 | Engine specifications

\begin{tabular}{ll}
\hline Engine type & \multicolumn{1}{c}{ Single cylinder } \\
\hline Cycle & 4 -stroke SI GDI \\
Valve per cylinder & 4 \\
Cylinder bore $(\mathrm{mm})$ & 84 \\
Piston stroke $(\mathrm{mm})$ & 90 \\
Displacement $(\mathrm{L})$ & 2.0 \\
Connecting rod length $(\mathrm{mm})$ & 144.3 \\
Compression ratio & $10.3: 1$ \\
Intake valve open & 50 CAD BTDC exhaust \\
Intake valve close & 143 CAD BTDC compression \\
Exhaust valve open & 145 CAD ATDC compression \\
Exhaust valve close & 58 CAD ATDC exhaust
\end{tabular}

wide range of work conditions (Hall et al., 2016; Chai et al., 2020). However, downsizing strategy also makes it easier to cause knock combustion and even pre-ignition phenomenon (Ma et al., 2014; d'Adamo et al., 2015). On the other hand, the GDI technology can increase the volumetric efficiency and compression ratio because of the direct injection charge cooling effect, reducing the compression temperature to minimize knock combustion and avoid the preignition phenomenon (Kasseris and Heywood, 2012; Wang et al., 2020). Besides, without port fuel film that troubles the PFI engine, the GDI engine has a better transient response (Li Y. et al., 2021; Awad et al., 2021). Overall, the GDI is crucial to synergy with downsizing and turbocharging to optimize power performance, fuel consumption, and emission performance (Huang et al., 2007; Liu and Dumitrescu, 2019).

IT is an important parameter that influences mixture formation significantly and, therefore, combustion and emission performance (Zeng et al., 2006; Liu J. et al., 2021). Since IT is one of the key roles in optimizing GDI engine performance, many researchers have focused on its effect on engine performance (Huang et al., 2003; Shi et al., 2020). Gong et al. (2021) studied IT and $\mathrm{CO}_{2}$ dilution on combustion and emissions of a stoichiometric GDI engine. The result shows that peak cylinder pressure, peak heat release rate, and peak cylinder temperature first increased, and then decreased as retarding IT. Their corresponding angle crank had opposite trends. Duan et al. (2020) used an experimental investigation of the single injection strategy and double injection strategy on the combustion phasing, performance, and emissions characteristics in the GDI engine. The result shows that with the increase of second IT, the PCP, Peak combustion pressure; , maximum HRR, Heat release rate, and mean in-cylinder temperature were gradually increased. HC emission gradually increased but much less than the single injection at the same condition. Zhang et al. (2012) experimentally investigated the effect of IT on GDI engine performance. The result shows that IT impacts the charging cooling effect, fuel film, combustion efficiency, and HC emission. Kim et al. (2013) studied the effect of injection strategy on soot emission, revealing that advancing second IT and decreasing second injection fuel mass can reduce soot emission. Li et al. (2021) investigated the spray characteristics, flame propagation, and other indicators of a 
TABLE 2 | Simulated operating conditions at various injection timings

\begin{tabular}{ll} 
Injection type & \multicolumn{1}{c}{ Pulsed } \\
\hline Start of injection (SOI) & $270,280,290$, and 300 CAD BTDC compression \\
Mean cone angle $\left(^{\circ}\right)$ & 14 \\
Injection duration (CAD) & 18.4 \\
Total injected mass (mg/cycle) & 21.1 \\
Engine speed ( $\mathrm{r} / \mathrm{min})$ & 2,000 \\
Spark timing & 15 CAD ATDC compression
\end{tabular}

GDI optical engine. The results showed that flash boiling injection resulted in lower apparent flame velocity and flame area compared with supercooled injection, which was due to the supercooled combustion conditions. Wen et al. (2020) studied the effects of fuel octane number on the fuel consumption rate and emissions of GDI and PFI spark-ignition (SI) engines. The results indicated that with the increase of research octane number (RON), the fuel consumption rate increases first and then decreases for GDI engines. Liu et al. (2019) investigated the effects of ethanol gasoline, $n$-butanol gasoline, and 2,5dimethylfuran (DMF) gasoline on the GDI engine efficiency and emissions. The results indicated that $n$-butanol gasoline is the best blended fuel among three kinds of oxygenated fuel blends for reducing harmful emissions and $\mathrm{CO}_{2}$ emissions.

However, previous research mainly focused on overall engine performance, and the literature about the incylinder mixture formation process and distribution of various emissions are limited (Yu et al., 2015; Sun et al., 2021). Moreover, the combustion process in the cylinder has been analyzed (Part A). Therefore, this paper is expected to analyze the in-cylinder view of mixture equivalence ratio, velocity field, and distribution of emissions to understand the effects of IT on engine efficiency and emissions better. A three-dimensional (3D) numerical computational fluid dynamics (CFD) simulation was adopted. It is hoped that this research will provide a more accurate view of how IT influences the mixture formation and then emissions, which contributes to optimizing the IT for better overall GDI engine performance (Zhu, 2019; Liu J. et al., 2021).

\section{NUMERICAL MODEL}

A single-cylinder four-stroke SI GDI engine model was studied with $3 \mathrm{D}$ engine software and the engine specifications are shown in Table 1. As Figure 1 shows, considering the computational cost, the research model includes half of the combustion chamber due to its symmetry. Computing domain includes intake, exhaust port and valve, spark plug, and combustion chamber that bounded by liner, symmetry, piston, and cylinder head. The computation mesh's global size was set to $0.2 \mathrm{~cm}$ and refined around key geometric features like valves and the spark plug.

The chemistry mechanism for gasoline that consists of 59 species and 437 reactions was imported from the software's built-in library (Dumitrescu et al., 2018; ANSYS Forte). The chemistry mechanism can simulate the gas phase and surface reactions and conclude gasphase input, gas-phase output, thermodynamic input, transport input, transport output, etc. (Li et al., 2019; Liu and Dumitrescu, 2020a). The simulation used the built-in precalculated laminar flamespeed table of ic8h18 to track the laminar flame front. To study the turbulent flame propagation, the Discrete Particle Ignition Kernel Flame model (DPIK) and G-equation were used. DPIK model that uses Lagrangian particles to mark the flame front position was used at the beginning of the spark when the ignition-kernel flame size is smaller than the mesh size (Harshavardhan and Mallikarjuna, 2015; Liu and Dumitrescu, 2020b). The turbulent flame propagation model will switch to G-equation after the flame size grows bigger than the mesh size. The G-equation model consisting of a set of Favreaveraged level-set equations is selected for its balance of time cost and accuracy (Liu and Dumitrescu, 2018; Chai et al., 2019). Reynoldsaveraged Navier-Stokes (RANS) is chosen as turbulent transport model, and RNG k-epsilon equation was employed since it has better performance than the k-epsilon model in engine combustion simulation (Lucchini et al., 2012; Stocchi et al., 2019). The G-equation, RANS, and RNG k-epsilon equation establishes a
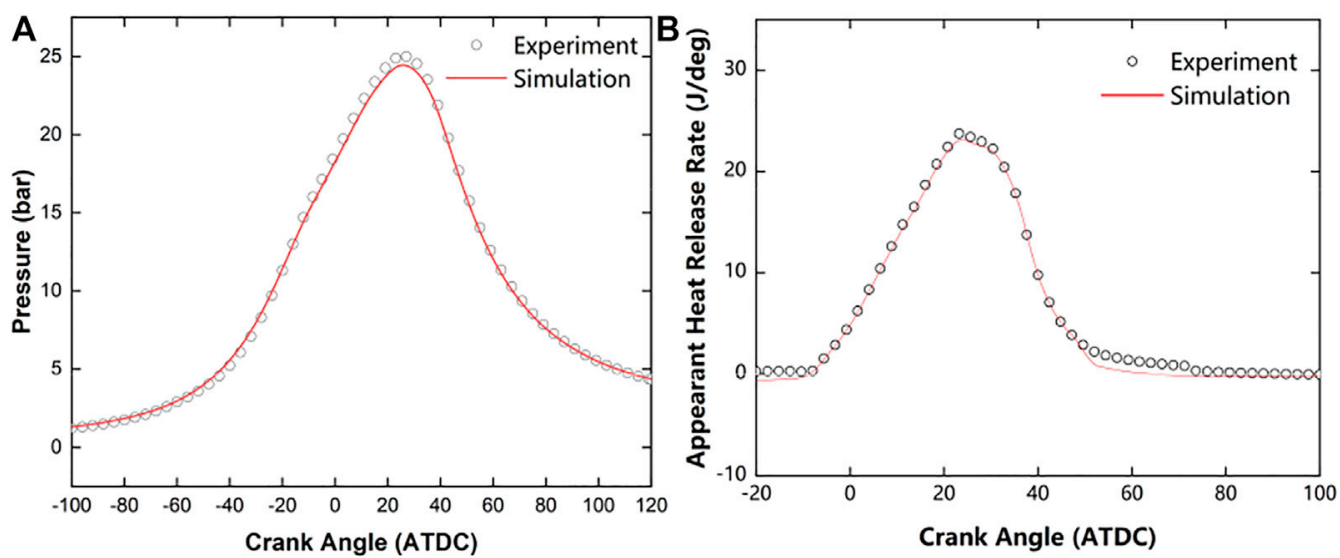

FIGURE 2 | The comparison of simulated data with measured data at the 300 CAD BTDC injection timing: (A) pressure trace and (B) apparent heat release rate curve. 


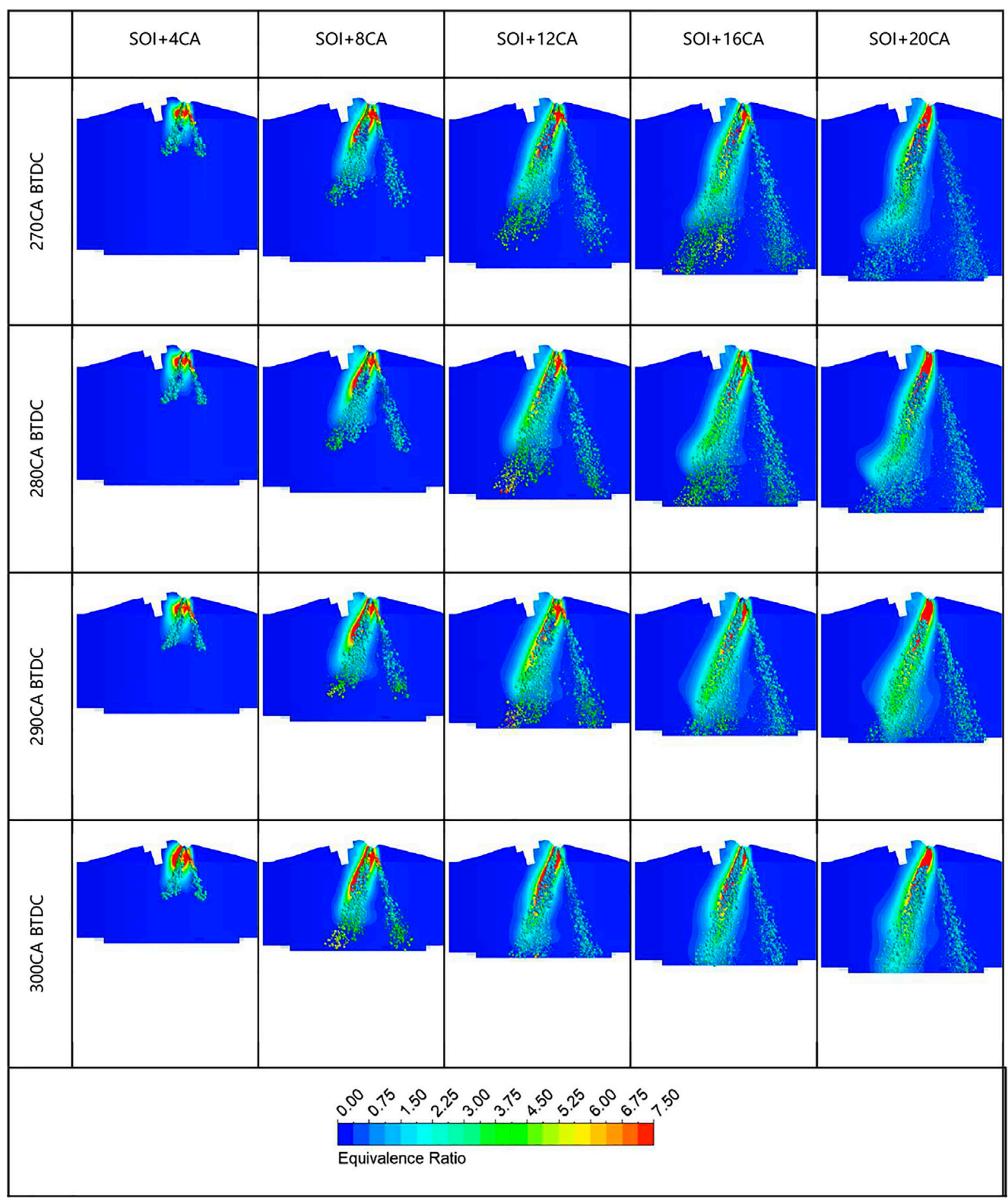

FIGURE 3 | Effect of injection timing on injection process at cylinder symmetry at several CA after SOI.

complete set of equations that describe turbulent flame propagation (Papageorgakis and Assanis, 1998; Bommisetty et al., 2018).

The spray model includes nozzle flow, spray atomization, droplet breakup, collision, coalescence, vaporization, and wall impingement (Zhu, 2019; Feng et al., 2021). The radius of influence model was chosen because of its independence on the CFD mesh size (Costa et al., 2014; Xu et al., 2020b). The model set up three injection nozzles and four ITs to research its effect on GDI engine performance, and Table 2 shows the detailed simulation operating conditions (Potenza et al., 2019; Liu Z. et al., 2021). 


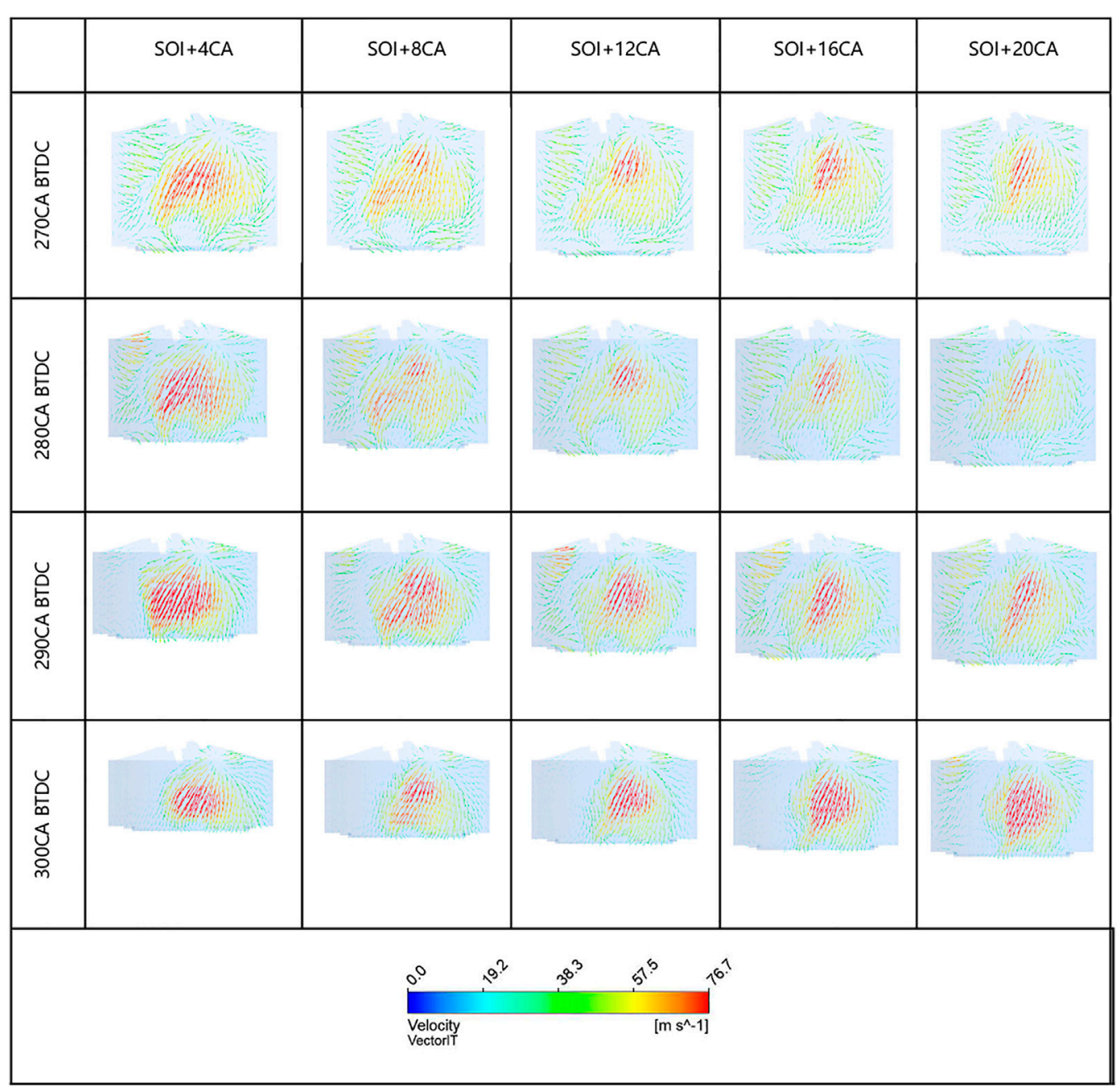

FIGURE 4 | Effect of injection timing on mixture formation at cylinder symmetry at several CA after SOI.

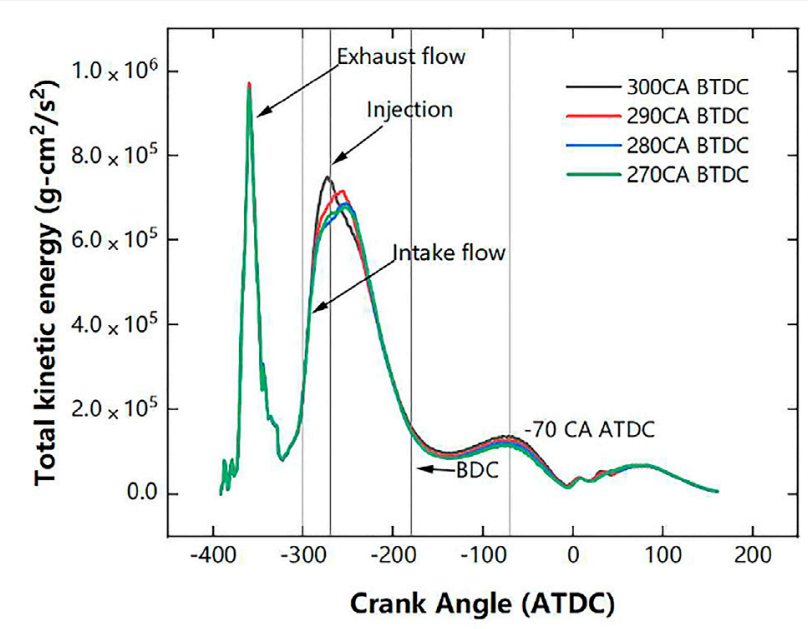

FIGURE 5 | Effect of injection timing on total kinetic energy.
The model was already validated against the experimental data at the condition shown in Table 2. Moreover, the comparison of measured cylinder pressure curve with simulated results is shown in Figure 2, which indicated that 3D CFD model was validated. The detailed model validation information can be found in Verma et al. (2016a) and Verma et al. (2016b).

\section{RESULTS AND DISCUSSION Injection Timing Effects on In-Cylinder Mixture Formation}

As can be seen in Figure 3, the symmetry was colored by the equivalence ratio and the balls, which were colored by velocity and size dependent with droplet diameter, were denoted as droplets. It is obvious that penetration distance of the droplets increased as the IT delayed, which was mainly determined by the difference of the distance between 


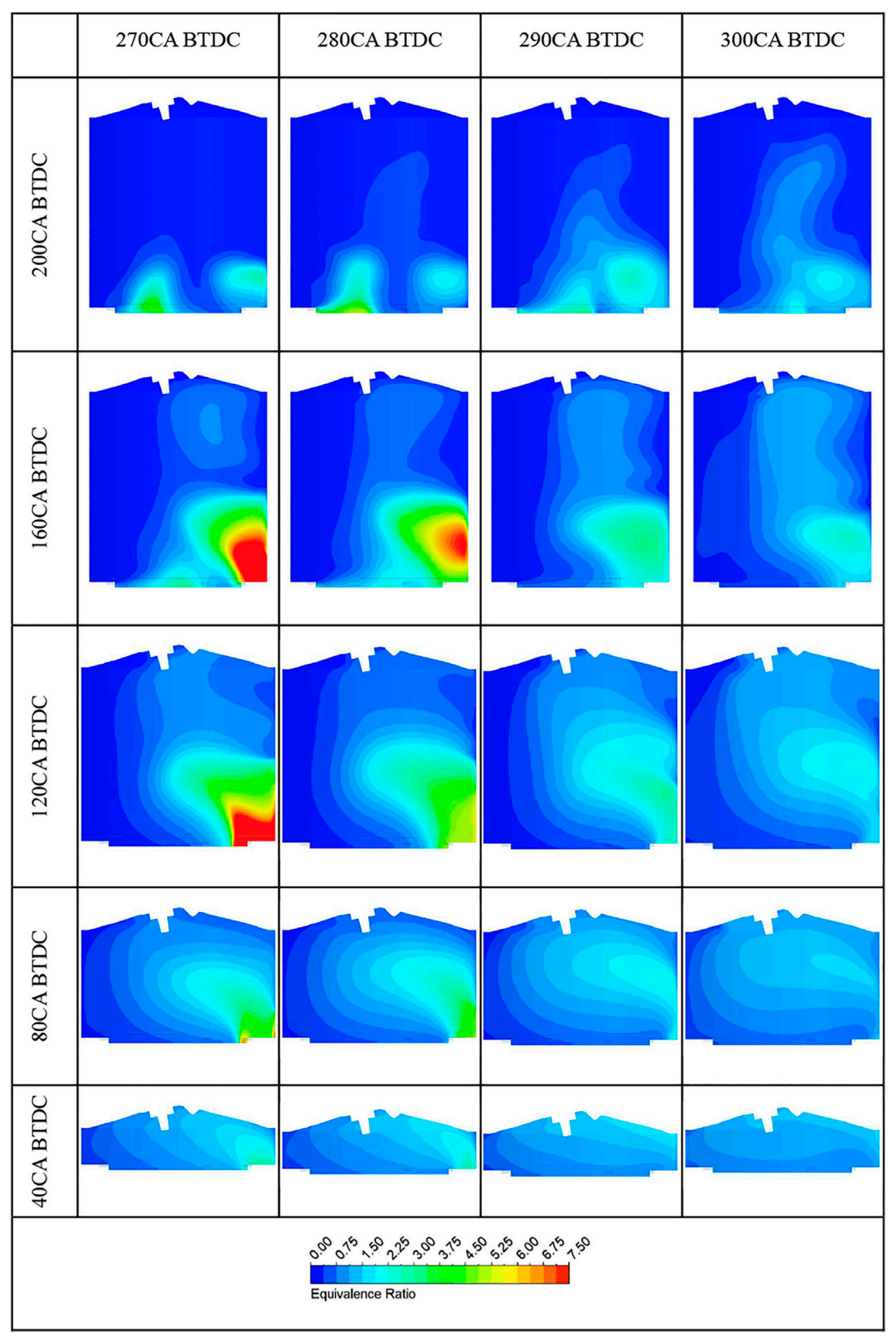

FIGURE 6 | Effect of injection timing on mixture formation at cylinder symmetry at several CAD before spark timing.

nozzles and piston surface. Besides, it was very important to note that the droplet-wall impingement intensified fiercely as the IT advanced, especially at IT of 300 CA BTDC. Also, the maximum equivalence ratio is about 7.5 , which is similar with the results in Chen et al. (2019). Figure 4 compares the velocity field during injection at different ITs. It is apparent 


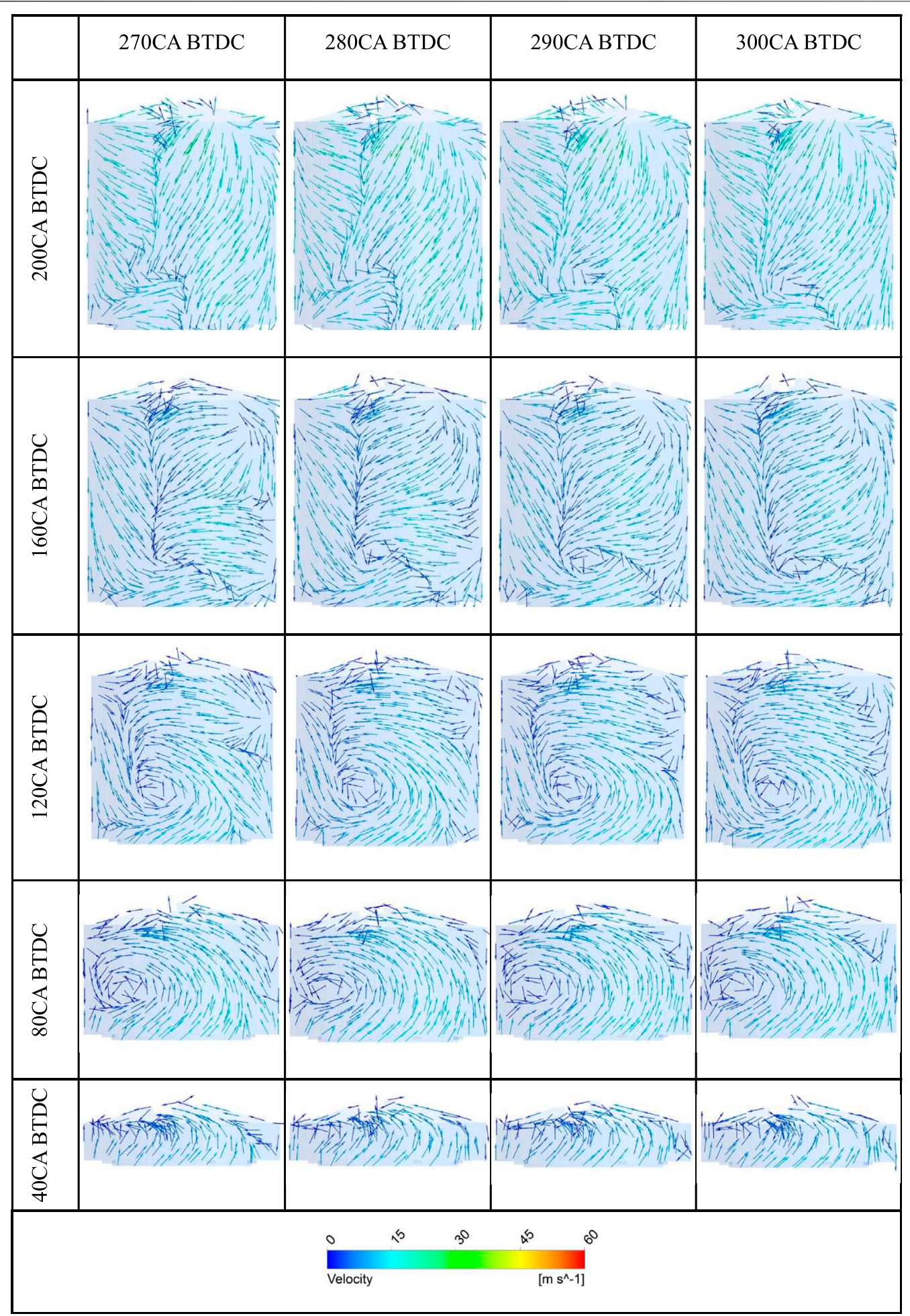

FIGURE 7 | Effect of injection timing on mixture velocity vector diagram at cylinder symmetry at several CAD before spark timing.

in Figure 4 that advancing IT corresponds to higher velocity and more intensified flow motion, which also can be inferred from Figure 5. The main reason for the difference in speed is the intake flow that is stronger at the beginning of intake stroke due to lower pressure. Figure 5 shows the effect of IT on total kinetic energy as the indicator of intensity of flow motion. The first peak was caused by exhaust flow and the second peak corresponded to intake flow. It was of interest to 


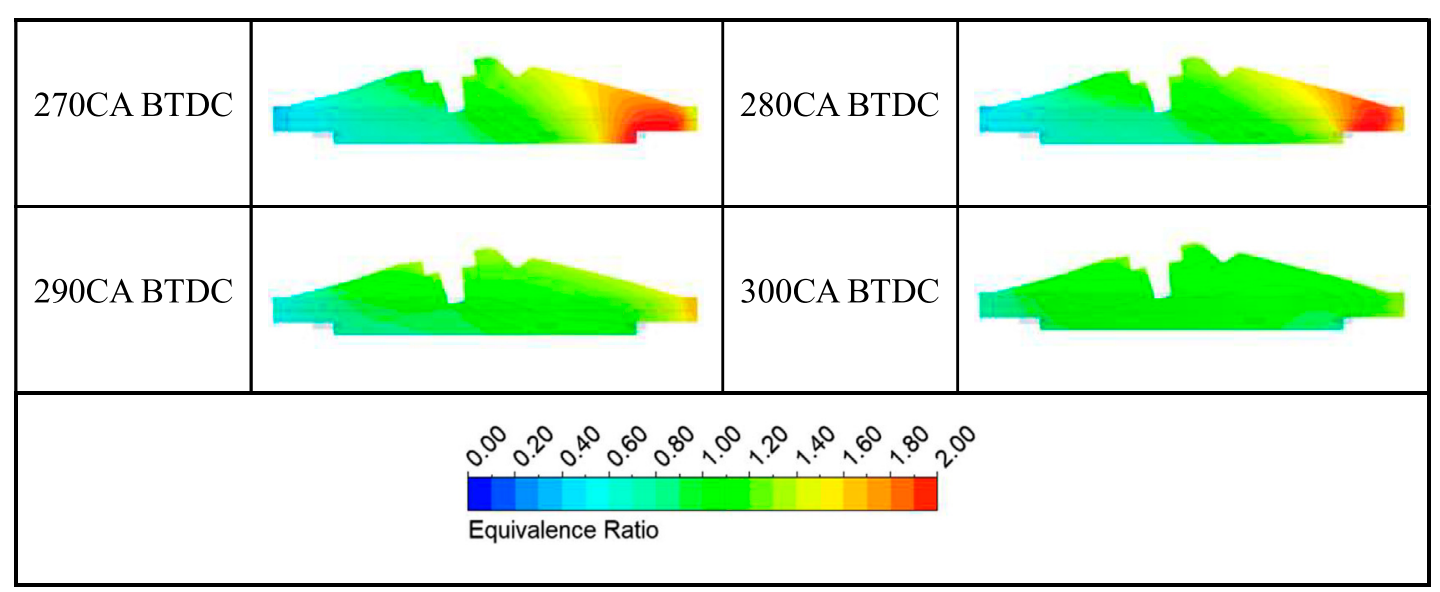

FIGURE 8 | Equivalence ratio and velocity field at cylinder symmetry when sparked at different injection timings.

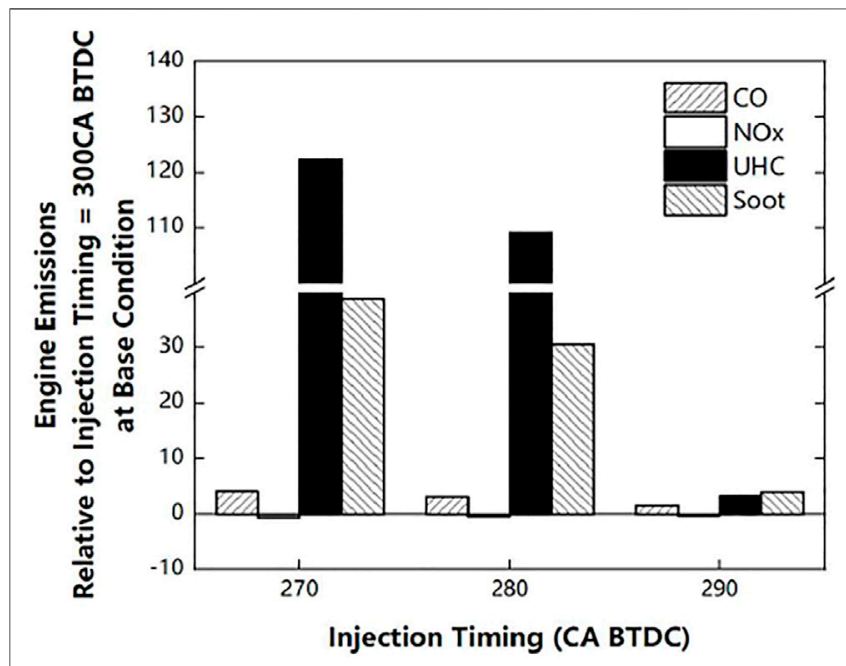

FIGURE 9 | Effect of injection timing on emissions.

point out that disturbance caused by injection at different IT has an apparent effect on the peak value of total kinetic energy. This was probably because the velocity direction of injected fuel was more similar with the in-cylinder flow motion at advanced IT, contributing to decrement of the dissipation of kinetic energy, which was supported by the combination of Figures 3 and 4.

To further study the fuel-gas mixture formation, the cylinder symmetry colored by equivalence ratio and velocity field is shown in Figures 6, 7. Different columns represent the incylinder fuel-gas mixture formation at various ITs and each row showed the results of different crank angles. At the beginning, the fuel-gas mixture accumulated on the piston surface, as expected, because of a collision phenomenon during the injection process. Significantly, an anticlockwise tumbling flow was formatted during the compression stroke. This tumbling flow drove the fuel-rich mixture near the piston to the intake side and head of the cylinder. Comparing the mixture formation at different ITs, advancing IT made the mixture more uniform, regardless of likely tumbling flow. The time spent on mixing seems to be the main reason for the difference between mixture uniformity. Because the earlier IT corresponds to longer in-cylinder mixing process, it also corresponds to a stronger degree of turbulence, which widens the gap in the mixing level, as shown in Figure 5. For example, the fuel-rich mixture of $300 \mathrm{CA}$ BTDC injection timing had moved to the center of the cylinder at 160 CA BTDC; meanwhile, the fuel-rich region of $270 \mathrm{CA}$ BTDC was still gathered around the surface of the piston.

From Figure 7, it can be found that the velocity distribution for different ITs were similar, indicating the little effect of IT on in-cylinder flow motion, which corresponded to the overlapping area of Figure 5. A clear anticlockwise tumbling flow was formed in the cylinder by the combined action of the piston and intake flow. Comparing Figures 6, 7, it can be found that the tumbling flow dominated in-cylinder mixture formation process. Consequently, as Figure 8 shows, the in-cylinder mixture formation results were colored by equivalence ratio. Also, the results at the IT of $300 \mathrm{CA}$ BTDC were satisfactory, while delayed IT corresponds to the fuel-rich region, especially at the IT of 270 and 280 . The gathered fuel mixture region was located at the intake side near the cylinder, which influenced combustion performance remarkably. This is because the flame can be ignited easily and propagate at the stoichiometry ratio region and excess equivalence ratio region tends to be slower, even freezing the flame propagation. Besides, it was of interest to note that the eq around spark plug is near stoichiometry ratio.

\section{Injection Timing Effects on Emission}

Nowadays, as environmental issues are gaining more attention and emission regulations are becoming stricter, 


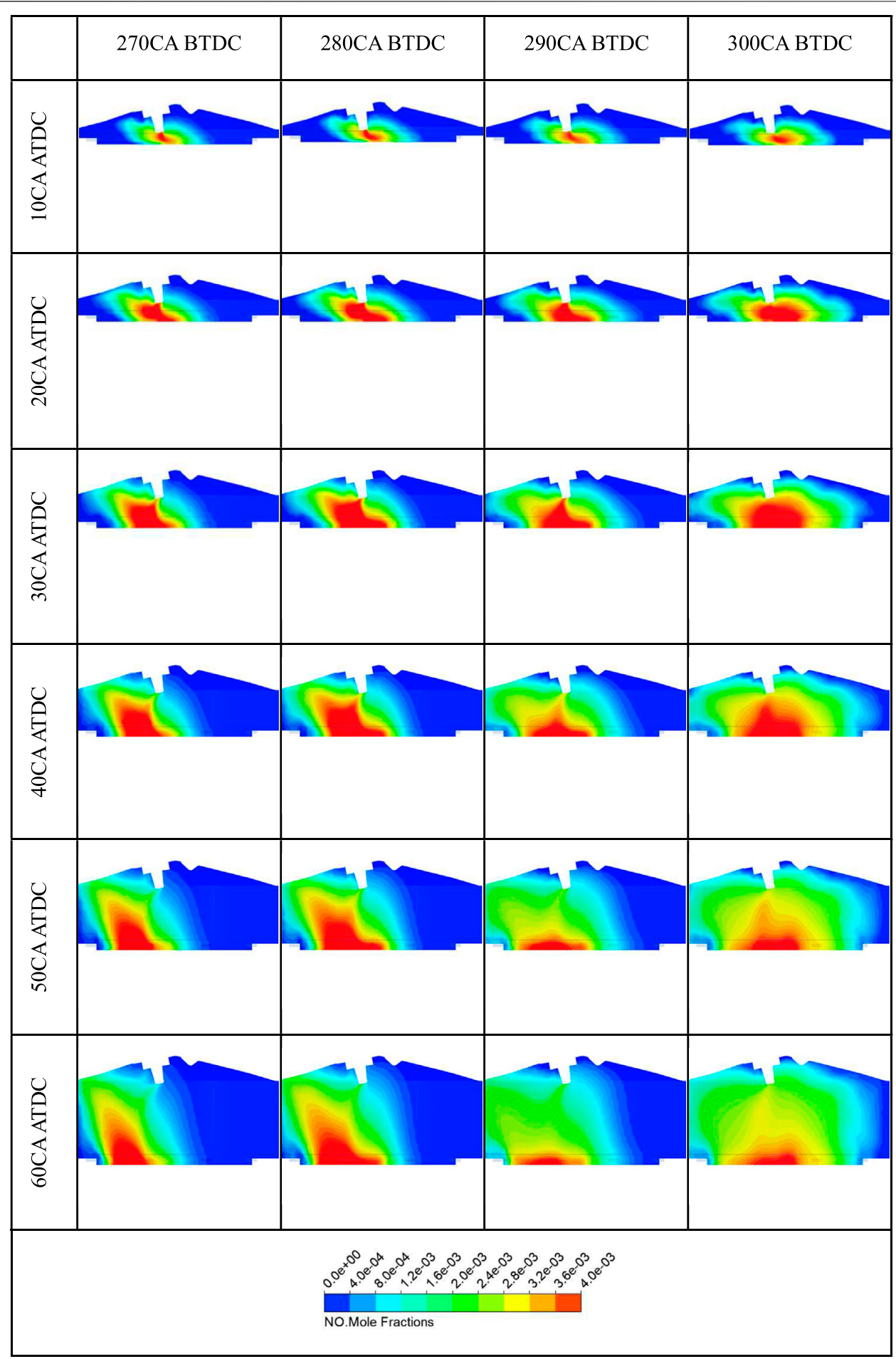

FIGURE 10 | Effect of injection timing on NOx emission at several CAD in combustion duration.

many researchers are exploring methods to improve engine efficiency and reduce emissions. It is a great way to use GDI engines to achieve the purpose of energy saving and emission reduction. However, if the operating parameters of the GDI engine are not well controlled, the
GDI engine will have higher emissions than the PFI engine, which is contrary to the original objective. Therefore, it is very important to investigate the in-cylinder emission formation and oxidation process. In this study, the generation of carbon monoxide (CO), unburned hydrocarbons (UHC), nitrogen oxides (NOx), and soot 


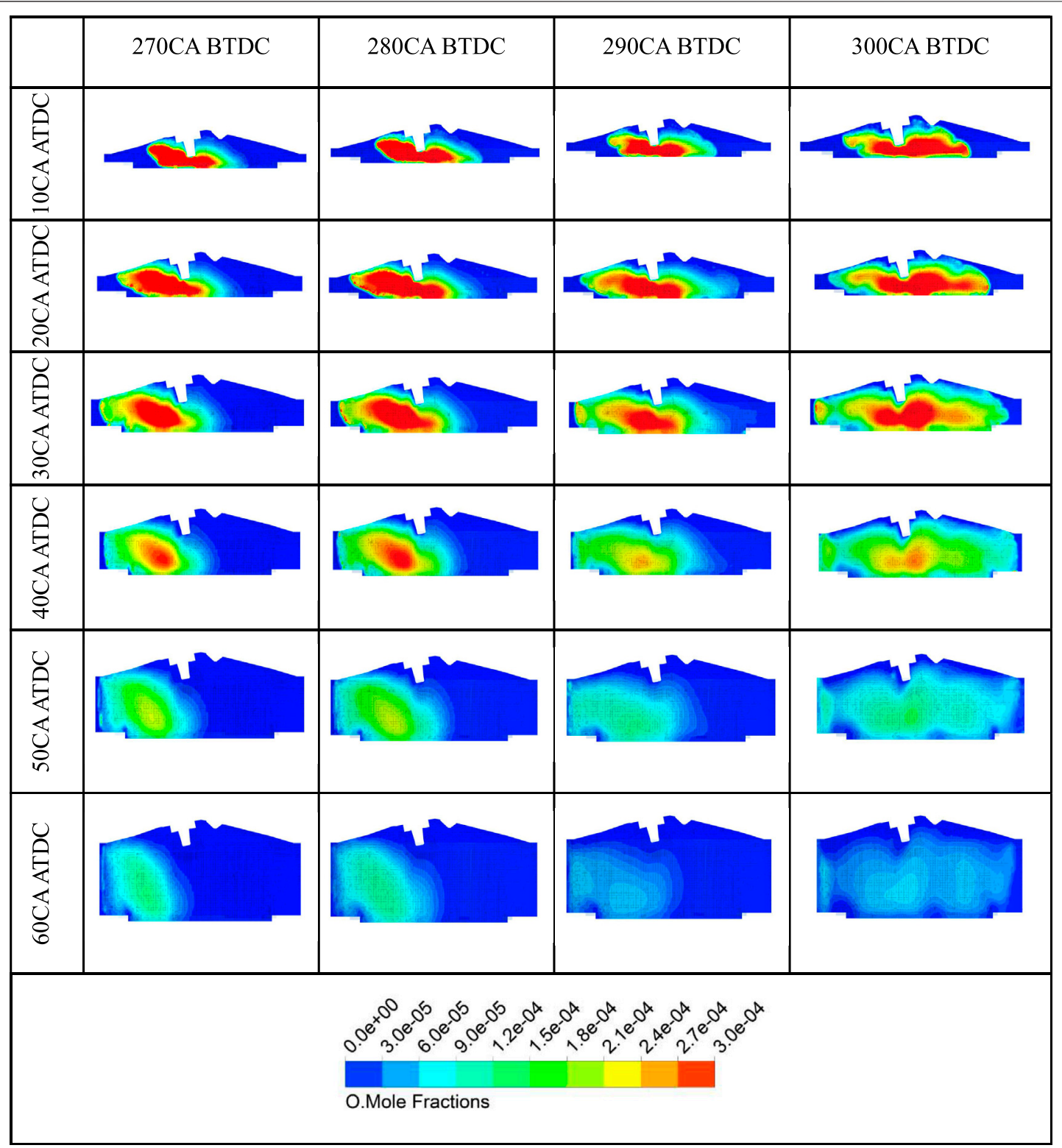

FIGURE 11 | Effect of injection timing on $O$ formation at several CAD in combustion duration.

has been investigated, although soot of gasoline engine is not in the emissions regulation.

Figure 9 shows the various species of emission variation at different ITs. UHC is most sensitive to IT, followed by soot. The UHC, soot, and $\mathrm{CO}$ emissions have a significant negative correlation with the advancing of IT, while NOx emission has an insensitive positive correlation. Overall, with the advancing IT from 270 to $300 \mathrm{CA}$ BTDC, the CO emission has decreased by $80.6 \%$, and UHC and soot had been reduced by $99.2 \%$ and $97.5 \%$, respectively; NOx emission had increased by $151.7 \%$. The next section will discuss the effect of IT on emissions.

To investigate the effect of IT on NOx generation, the $3 \mathrm{D}$ clouds and graphs of NOx and oxygen radicals in the cylinder at different injection angles are as follows. Nitrogen oxides (NOx) and hydrocarbons (HC) under strong sunlight, through a series of chain photochemical reactions, will generate ozone $\left(\mathrm{O}_{3}\right)$ and peroxyacetyl nitrate (PAN), that is, the generation of secondary pollutants such as photochemical smog (Duronio et al., 2020). Also, the smog is highly oxidizing and causes stinging eyes, strong respiratory irritation, dizziness, and vomiting. Also, it is very harmful for both plants and the atmosphere. Therefore, it is necessary to study the process of NOx generation at different injection advanced angles.

$\mathrm{NOx}$ mainly consists of $\mathrm{NO}$ and $\mathrm{NO}_{2}$, and the engine combustion process mainly produces $\mathrm{NO}$ and a small amount 


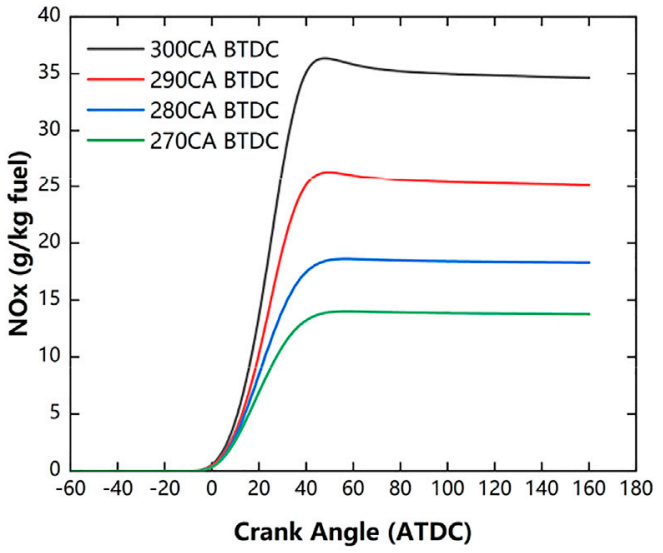

FIGURE 12 | Effect of injection timing on NOx formation. of $\mathrm{NO}_{2}$ (Ambrogi et al., 2019). It is generally known that $\mathrm{NO}$ accounts for more than $90 \%$ of NOx and 3D diagram mainly discusses the NO to replace the NOx. Also, the NO calculation is based on the extended Zeldovich mechanism. The $\mathrm{NO}$ oxidation rate, $\mathrm{N}$ oxidation rate, and $\mathrm{OH}$ reduction rate equations are based on Eqs 1-3, respectively.

$$
\begin{gathered}
\mathrm{O}+\mathrm{N}_{2}=\mathrm{NO}+\mathrm{N} \\
\mathrm{N}+\mathrm{O}_{2}=\mathrm{NO}+\mathrm{O} \\
\mathrm{N}+\mathrm{OH}=\mathrm{NO}+\mathrm{H}
\end{gathered}
$$

The condition of NOx formation includes high temperature, oxygen concentration, and reaction time (Ambrogi et al., 2019; Duronio et al., 2020). Figure 10 shows that the NOx emission had increased considerably with the IT advancing. Moreover, NOx was first generated around the spark plug and then mainly generated at the exhaust side of the combustion chamber.

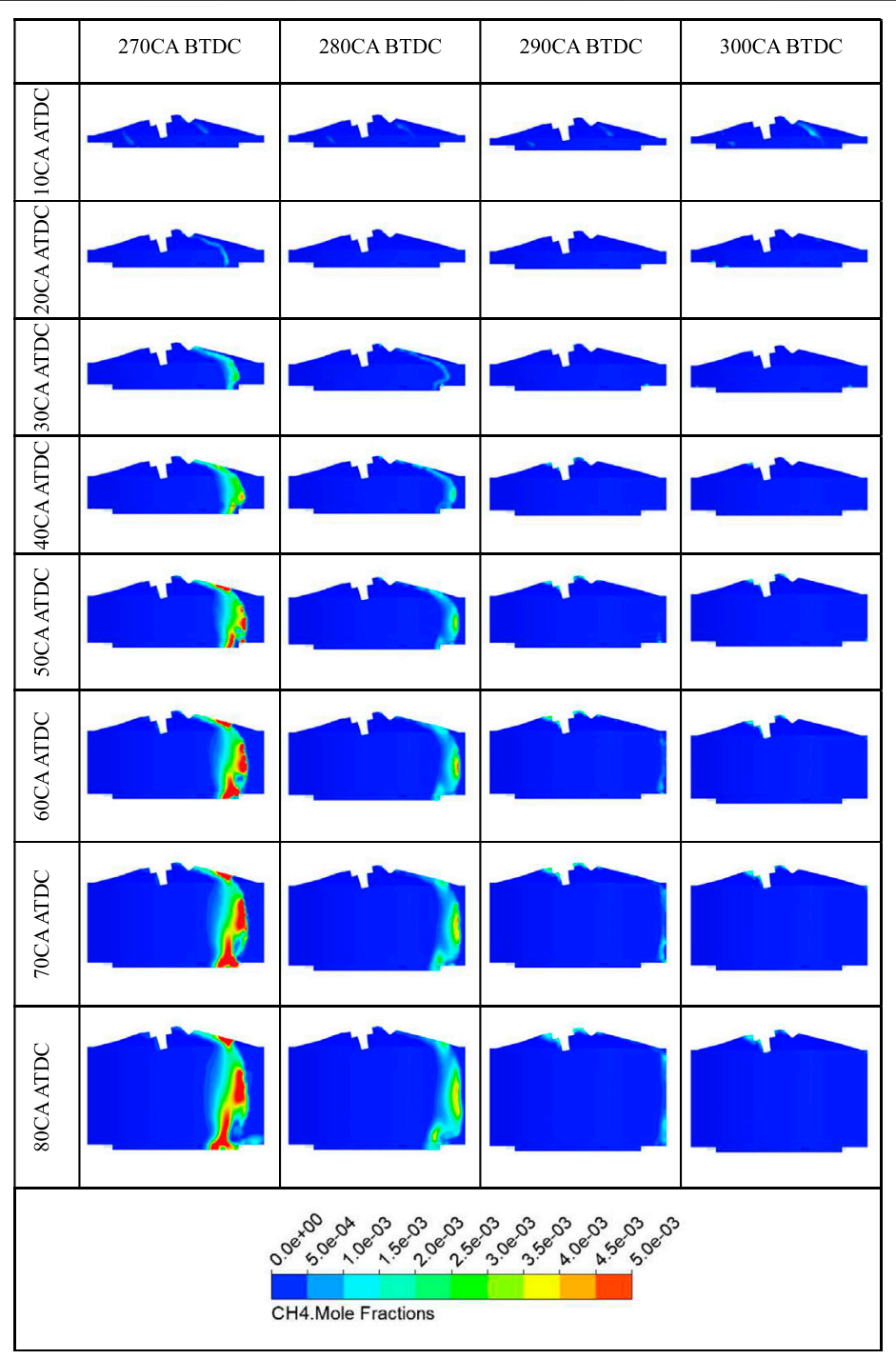

FIGURE 13 | Effect of injection timing on UHC emission. 


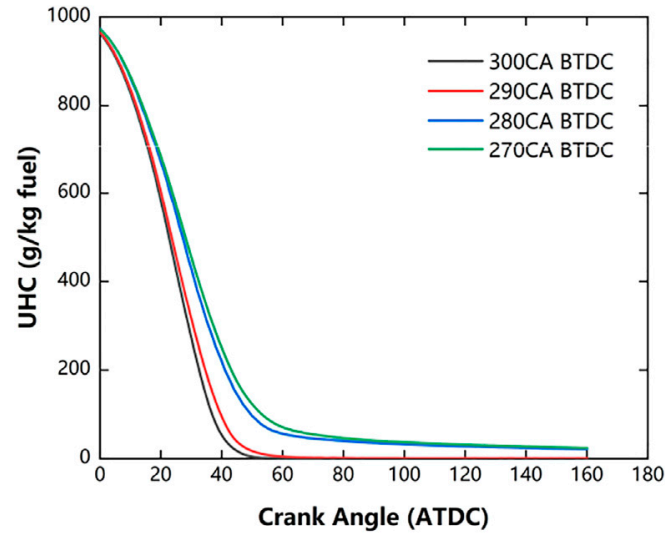

FIGURE 14 | Effect of injection timing on UHC formation.
Considering the conditions of NOx formation, Figure 11 shows the cylindrical symmetry with $\mathrm{O}$ as the color, leading to the conclusion that NOx is mainly produced in the region of high temperature and high oxygen concentration. Comparison with mixture formation and combustion mentioned in the next section reveals that the flame speed variation at different combustion chamber sides resulted in higher temperature. Those regions where the equivalence ratio was close to the stoichiometric ratio have faster combustion speed and higher oxygen concentration than the fuel-rich region, leading to more $\mathrm{NOx}$ formation.

To further study the correlation between NOx formation and IT, Figure 12 is used to show the NOx formation at different ITs. Advanced ITs indicated more uniform in-cylinder mixture, better combustion performance, and higher temperature. As the temperature increased with advanced IT, the NOx rising is mainly caused by increasing in-cylinder temperature with

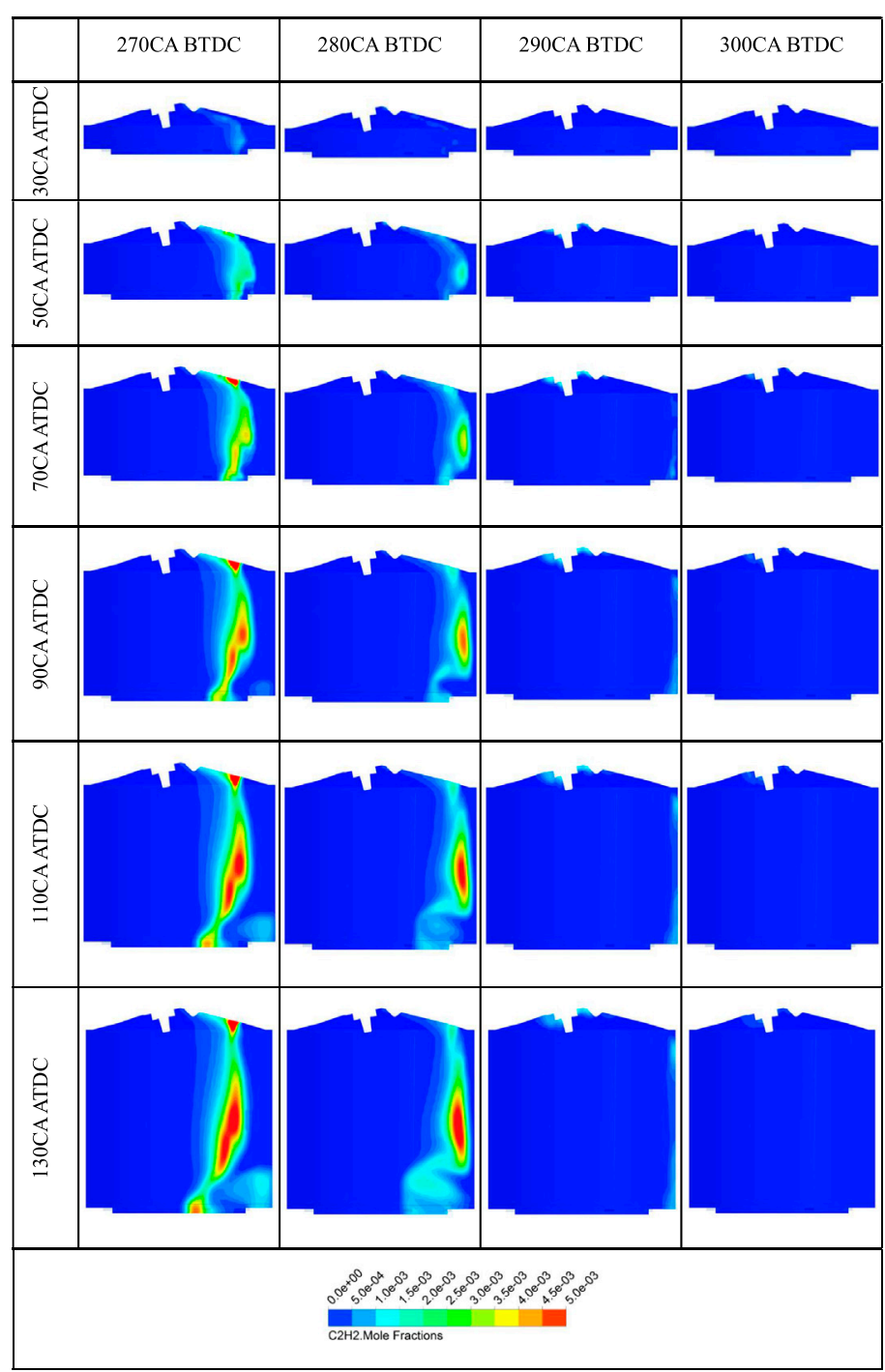

FIGURE 15 | Effect of injection timing on soot generation at several CAD in combustion duration. 


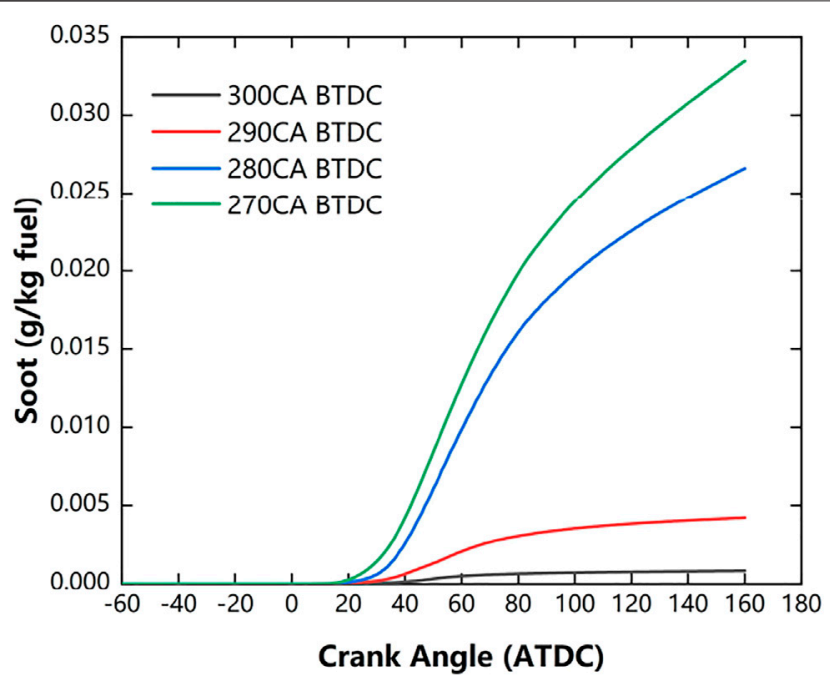

FIGURE 16 | Effect of injection timing on soot formation.

similar generated oxygen radical, as expected. As mentioned previously, advancing IT resulted in more uniform fuel mixture, improved combustion performance, and eventually increased NOx emission.

There are three main pathways for $\mathrm{HC}$ generation: incomplete combustion, wall quenching, and wall-moving film adsorption (Ambrogi et al., 2019; Duronio et al., 2020). For incomplete combustion, unburned hydrocarbon (UHC) emissions may be due to uneven oil-gas mixing, misfires, and other phenomena. For wall quenching, it is the major reason for UHC generation. There are various narrow gaps in the combustion chamber, especially the chamber seam between the piston head and the cylinder wall, etc. In the compression stroke, some fuel mixture was compressed into the crevice attributed to the high pressure in the cylinder. Moreover, the quenching effect is very strong due to the crevice with large surface-to-volume ratio. Also, the flame cannot spread into the crevice to continue to burn. Moreover, during the expansion and exhaust stroke, the cylinder pressure drops and the unburned mixture in the gap is exhausted along with the exhaust gas. For oil film adsorption, lubricant oil film on cylinder wall surface and carbon buildup on intake and exhaust valves will absorb the unburned gas mixture during the intake and compression strokes. Also, in the expansion and exhaust stroke, the UHCs will be released in the cylinder. In this study, $\mathrm{CH}_{4}$ was used to represent $\mathrm{UHC}$ due to the fact that $\mathrm{CH}_{4}$ has a strong chemical bonding.

UHC emission has a significant correlation with IT, as shown in Figures 13, 14. $\mathrm{CH}_{4}$ as an indicator of UHC is mainly produced at the flame front on the intake side, where the mixture combusted incompletely. With the IT advancing, the UHC has decreased. Figure $\mathbf{1 3}$ indicates that the fuel-rich mixture that did not fire may not be the main reason for the rapid increase of UHC. Considering the previous section, the fuel-rich mixture region, which is especially obvious at 270 and

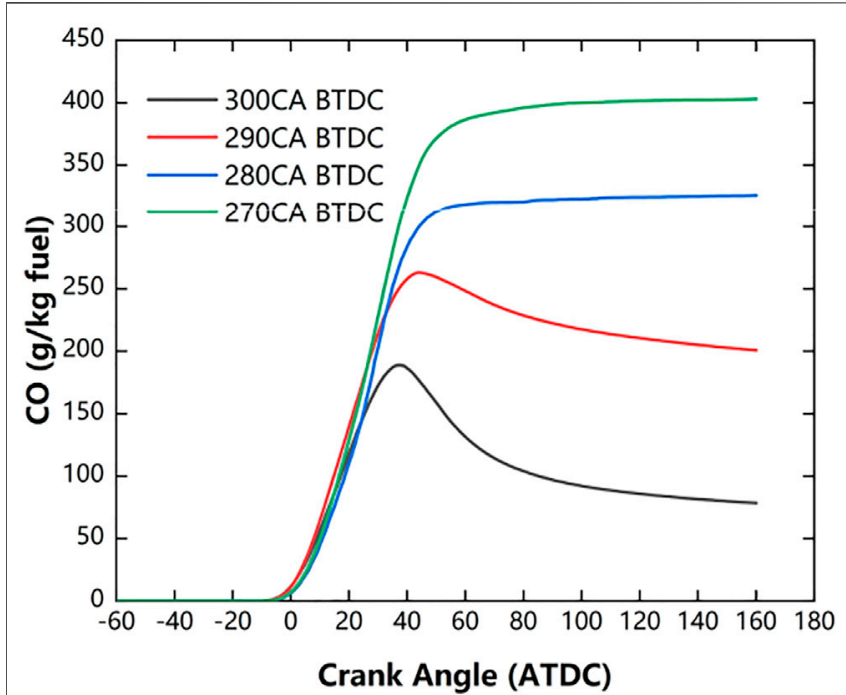

FIGURE 17 | Effect of injection timing on $\mathrm{CO}$ emission.

280 CA BTDC, resulted in an unburnt area. Hence, UHC has a sensitive correlation with IT.

The soot emissions of conventional PFI engines come from fuel combustion. Also, when there are droplets on the wall in the combustion chamber, GDI engines will generate soot due to the fact that the after-treatment system only has a three-way catalyst (TWC), but no DPF (diesel particulate filter). Soot is mainly composed of $\mathrm{PM}_{2.5}$ and $\mathrm{PM}_{10}$, of which $\mathrm{PM}_{2.5}$ is the most harmful to the human body and environment. Therefore, the soot investigated in this study is mainly $\mathrm{PM}_{2.5}$, which is represented by $\mathrm{C}_{2} \mathrm{H}_{2}$ ( $\mathrm{Yu}$ et al., 2017). Moreover, the soot is hazardous to human health and reduces atmospheric visibility, which is harmful to the human respiratory system and may cause symptoms such as asthma and cancer. Also, soot will create carbon deposits that decrease the efficiency of the aftertreatment. Hence, the soot needs to be eliminated as much as possible and the study of soot generation is very necessary.

GDI engine has more soot emission than traditional PFI engine due to higher wall temperature (Wang and Shen, 2021b; Yu et al., 2022). Using $\mathrm{C}_{2} \mathrm{H}_{2}$ as an indicator, Figure 15 shows the soot formation at different ITs. As can be seen from Figure 15, soot emission increased rapidly as IT delayed. Moreover, soot is first formatted around the nozzle and then mainly formatted at the intake side of the flame front, especially at 270 and 280 CA BTDC. As mentioned previously, on the intake side of the combustion chamber, at 270 and $280 \mathrm{CA}$ BTDC, the incomplete combustion of the fuel mixture is severe, even without ignition, causing a significant increase in soot formation. Besides, it can be also found in Figure 16 that as IT advanced, less soot was generated. This is because the in-cylinder mixture was more uniform at earlier IT, thus improving the combustion performance. 


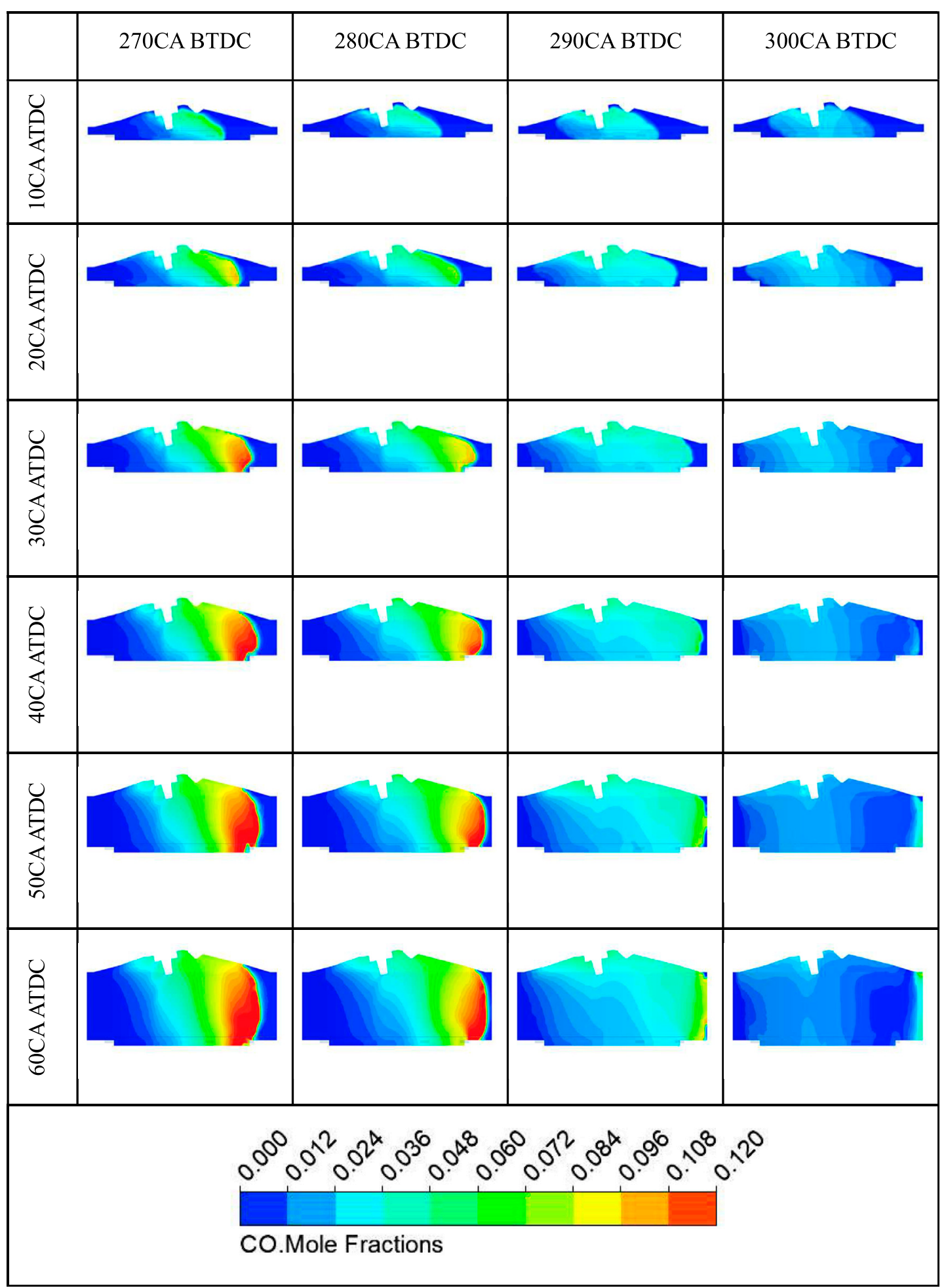

FIGURE 18 | Effect of injection timing on CO generation at several CAD in combustion duration.

It is commonly recognized that the affinity between $\mathrm{CO}$ and hemoglobin $(\mathrm{Hb})$, which is the carrier of oxygen delivery in blood, is 200-300 times higher than $\mathrm{O}_{2}$ (Duronio et al.,
2020). Also, it can easily combine $\mathrm{Hb}$ to form carboxyhemoglobin $(\mathrm{CO}-\mathrm{Hb})$, which greatly reduces the oxygen delivery capacity of blood and leads to serious 
oxygen deprivation in the heart, brain, and other vital organs. In addition, $\mathrm{CO}$ is a product of incomplete combustion and is produced due to the unevenness of the in-cylinder mixture and wall quenching effect in the crevice of the combustion chamber. Therefore, it is of great significance to investigate the incylinder $\mathrm{CO}$ concentration distribution at different ITs, which can be used as a reference to explore how to reduce $\mathrm{CO}$ emissions from GDI engines.

Figures 17, 18 show the CO formation at different ITs. From Figure 17, it can be seen that $\mathrm{CO}$ emission was increased with the delayed IT. Furthermore, the results indicated that $\mathrm{CO}$ is probably mainly produced at the flame front and severely at the intake side at 270 and 280 CA BTDC injection timing where fuel-gas mixture combusted incompletely. This is because the equivalence ratio of the intake side area at the spark timing was much higher than stoichiometry ratio at 270 and 280 CA BTDC injection timing, as can be seen in Figure 8. As mentioned previously, the homogeneity of the mixture varied obviously with advancing IT. Fuel gathered at the intake side of the combustion chamber as IT delayed. As a result, the incomplete combustion was intensified, especially at 270 and 280 CA BTDC injection timing. Eventually, the total CO emission was increased due to non-uniform fuel mixture and incomplete combustion. Consequently, with the delayed injection timing, the CO produced at the intake side was markedly increased and total $\mathrm{CO}$ emission was the most at the IT of 270 CA BTDC.

\section{SUMMARY AND CONCLUSION}

This paper set out to study the effect of IT on mixture formation and emission performance. By analyzing the numerical CFD simulation results at different ITs, the research showed that advancing IT leads to a more uniform fuel-gas mixture and hence reduces the $\mathrm{UHC}$, soot, and $\mathrm{CO}$ emission sharply but gradually increases NOx emission. The results indicated that with the IT advancing, the fuel mixed more uniformly under the effect of tumbling flow, which is hardly influenced by IT. Therefore, the time available for fuel-gas mixed seems to be the main reason for the different uniform mixture. As for emissions, when advancing the IT, and the UHC emission had reduced sharply. The fuel-rich region of the mixture at delayed IT combusted incompletely or

\section{REFERENCES}

Ambrogi, L., Liu, J., Battistoni, M., Dumitrescu, C., and Gasbarro, L. (2019). CFD Investigation of the Effects of Gas' Methane Number on the Performance of a Heavy-Duty Natural-Gas Spark-Ignition Engine. SAE Technical Paper. SAE Technical Paper 2019-24-0008. doi:10.4271/2019-24-0008

Anbari Attar, M., Herfatmanesh, M. R., Zhao, H., and Cairns, A. (2014). Experimental Investigation of Direct Injection Charge Cooling in Optical GDI Engine Using Tracer-Based PLIF Technique. Exp. Therm. Fluid Sci. 59, 96-108. doi:10.1016/j.expthermflusci.2014.07.020

ANSYS ${ }^{\circledR}$ Forte. User Guide. United States: Ansys, Inc.

Awad, O., Xiao, M., Kamil, M., Bo, Z. H., Ali, O. M., and Shuai, S. (2021). A Review of the Effects of Gasoline Detergent Additives on the Formation of Combustion even not on fire, resulting in a rapid increase of UHC emission. Moreover, the soot emission decreased by $97.5 \%$, and improvement in combustion efficiency is the main reason. Also, the NOx emission has increased by $151.7 \%$. As the advancing IT, the more uniform mixture was formed, which resulted in better combustion performance and higher incylinder temperature, and therefore increased NOx emission. Furthermore, the CO emission decreased by $80.6 \%$. The incylinder more uniform fuel mixture is the main reason for the decrement of $\mathrm{CO}$ emission.

Overall, this study contributes to understanding how IT influences mixture formation and various species of emissions. As far as this study is concerned, $300 \mathrm{CA}$ BTDC is the optimized IT. Considering the different models and conditions of various GDI engines, the optimized IT cannot be determined simply the same as this investigation. Moreover, this paper provides a reference to optimize the IT of the GDI engine to enhanced power performance and reduced emissions.

\section{DATA AVAILABILITY STATEMENT}

The raw data supporting the conclusion of this article will be made available by the authors, without undue reservation.

\section{AUTHOR CONTRIBUTIONS}

YZ: conceptualization, methodology, simulation, writing-draft preparation. RY: validation, writing-draft preparation. YY: methodology, simulation. RL: writing-draft preparation. ZL: writing-draft preparation. JF: analysis, supervision.

\section{FUNDING}

The work was jointly funded by the Natural Science Foundation of Zhejiang Province (LQ20E060003), the Project Teacher Research Fund Project (J-202116), and Projects of Hangzhou Agricultural and Social Development Research Program (20201203B128, 20212013B04).

Chamber Deposits of Gasoline Direct Injection Engines. SAE Int. J. Fuels Lubricants 14 (04-14-01-0002), 13-25. doi:10.4271/04-14-01-0002

Bommisetty, H., Liu, J., Kooragayala, R., and Dumitrescu, C. (2018). Fuel Composition Effects in a CI Engine Converted to SI Natural Gas Operation. SAE Technical Paper. SAE Technical Paper 2018-01-1137. doi:10.4271/201801-1137

Chai, M., Luo, K., Shao, C., Wang, H., and Fan, J. (2020). A Finite Difference Discretization Method for Heat and Mass Transfer with Robin Boundary Conditions on Irregular Domains. J. Comput. Phys. 400, 108890. doi:10. 1016/j.jcp.2019.108890

Chai, M., Luo, K., Shao, C., Wang, H., and Fan, J. (2019). Interface-resolved Detailed Numerical Simulation of Evaporating Two-phase Flows with Robin Boundary Conditions on Irregular Domains. Int. J. Heat Mass Transfer 145, 118774. doi:10.1016/j.ijheatmasstransfer.2019.118774 
Chai, M., Luo, K., Wang, H., Zheng, S., and Fan, J. (2021). Imposing Mixed Dirichlet-Neumann-Robin Boundary Conditions on Irregular Domains in a Level Set/ghost Fluid Based Finite Difference Framework. Comput. Fluids 214, 104772. doi:10.1016/j.compfluid.2020.104772

Chen, B., Feng, L., Wang, Y., Ma, T., Liu, H., Geng, C., et al. (2019). Spray and Flame Characteristics of wall-impinging Diesel Fuel spray at Different wall Temperatures and Ambient Pressures in a Constant Volume Combustion Vessel. Fuel 235, 416-425. doi:10.1016/j.fuel.2018.07.154

Costa, M., Marchitto, L., Merola, S. S., and Sorge, U. (2014). Study of Mixture Formation and Early Flame Development in a Research GDI (Gasoline Direct Injection) Engine through Numerical Simulation and UV-Digital Imaging. Energy 77, 88-96. doi:10.1016/j.energy.2014.04.114

d'Adamo, A., Breda, S., Fontanesi, S., and Cantore, G. (2015). LES Modelling of Spark-Ignition Cycle-To-Cycle Variability on a Highly Downsized DISI Engine. SAE Int. J. Engines 8 (5), 2029-2041. doi:10.4271/2015-24-2403

Duan, X., Li, Y., Liu, Y., Liu, J., Wang, S., and Guo, G. (2020). Quantitative Investigation the Influences of the Injection Timing under Single and Double Injection Strategies on Performance, Combustion and Emissions Characteristics of a GDI SI Engine Fueled with Gasoline/ethanol Blend. Fuel 260, 116363. doi:10.1016/j.fuel.2019.116363

Dumitrescu, C. E., Padmanaban, V., and Liu, J. (2018). An Experimental Investigation of Early Flame Development in an Optical Spark Ignition Engine Fueled with Natural Gas. J. Eng. Gas Turbines Power 140 (8), 082802. doi:10.1115/1.4039616

Duronio, F., De Vita, A., Montanaro, A., and Villante, C. (2020). Gasoline Direct Injection Engines - A Review of Latest Technologies and Trends. Part 2. Fuel 265, 116947. doi:10.1016/j.fuel.2019.116947

Feng, L., Sun, X., Pan, X., Yi, W., Cui, Y., Wang, Y., et al. (2021). Gasoline spray Characteristics Using a High Pressure Common Rail Diesel Injection System by the Method of Laser Induced Exciplex Fluorescence. Fuel 302, 121174. doi:10. 1016/j.fuel.2021.121174

Gasbarro, L., Liu, J., Dumitrescu, C., Ulishney, C., Battistoni, M., and Ambrogi, L. (2019). Heavy-Duty Compression-Ignition Engines Retrofitted to Spark-Ignition Operation Fueled with Natural Gas. SAE Technical Paper. doi:10.4271/2019-240030

Gong, C., Si, X., and Liu, F. (2021). Combined Effects of Excess Air Ratio and EGR Rate on Combustion and Emissions Behaviors of a GDI Engine with CO2 as Simulated EGR (CO2) at Low Load. Fuel 293, 120442. doi:10.1016/j.fuel.2021.120442

Hall, J., Bassett, M., Hibberd, B., and Streng, S. (2016). Heavily Downsized Demonstrator Engine Optimised for CNG Operation. SAE Int. J. Engines 9 (4), 2250-2261. doi:10.4271/2016-01-2363

Han, D., Fan, Y., Sun, Z., Nour, M., and Li, X. (2020). Combustion and Emissions of Isomeric Butanol/gasoline Surrogates Blends on an Optical GDI Engine. Fuel 272, 117690. doi:10.1016/j.fuel.2020.117690

Harshavardhan, B., and Mallikarjuna, J. M. (2015). Effect of Piston Shape on incylinder Flows and Air-Fuel Interaction in a Direct Injection Spark Ignition Engine - A CFD Analysis. Energy 81, 361-372. doi:10.1016/j.energy.2014. 12.049

Heywood, J. B. (2018). Internal Combustion Engine Fundamentals. McGraw-Hill Education.

Hongliang, Y., Shulin, D., and Peiting, S. (2016). Effects of Main/pilot Timings on Combustion and Emission Characteristics of marine Dual Fuel Engines. J. Propulsion Techn. 37 (9), 1735-1741.

Huang, Z., Shiga, S., Ueda, T., Nakamura, H., Ishima, T., Obokata, T., et al. (2003). Effect of Fuel Injection Timing Relative to Ignition Timing on the Natural-Gas Direct-Injection Combustion. J. Eng. Gas Turbines Power 125 (3), 783-790. doi:10.1115/1.1563243

Huang, Z., Wang, J., Liu, B., Zeng, K., Yu, J., and Jiang, D. (2007). Combustion Characteristics of a Direct-Injection Engine Fueled with Natural Gas-Hydrogen Blends under Different Ignition Timings. Fuel 86 (3), 381-387. doi:10.1016/j.fuel.2006.07.007

Kasseris, E., and Heywood, J. B. (2012). Charge Cooling Effects on Knock Limits in SI DI Engines Using Gasoline/ethanol Blends: Part 2-effective Octane Numbers. SAE Int. J. Fuels Lubr. 5 (2), 844-854. doi:10.4271/2012-01-1284

Keskinen, K., Kaario, O., Nuutinen, M., Vuorinen, V., Künsch, Z., Liavåg, L. O., et al. (2016). Mixture Formation in a Direct Injection Gas Engine: Numerical Study on Nozzle Type, Injection Pressure and Injection Timing Effects. Energy 94, 542-556. doi:10.1016/j.energy.2015.09.121

Kim, Y., Kim, Y., Jun, S., Lee, K. H., Rew, S., Lee, D., et al. (2013). Strategies for Particle Emissions Reduction from GDI Engines. SAE Tech. Pap. 2. doi:10.4271/ 2013-01-1556
Lake, T., Stokes, J., Murphy, R., Osborne, R., and Schamel, A. (2004). Turbocharging Concepts for Downsized DI Gasoline Engines. SAE Technical Paper.

Leduc, P., Dubar, B., Ranini, A., and Monnier, G. (2003). Downsizing of Gasoline Engine: an Efficient Way to Reduce CO2 Emissions. Oil Gas Sci. Techn. - Rev. IFP 58 (1), 115-127. doi:10.2516/ogst:2003008

Li, Y., Duan, X., Liu, Y., Liu, J., Guo, G., and Tang, Y. (2019). Experimental Investigation the Impacts of Injection Strategies Coupled with Gasoline/ethanol Blend on Combustion, Performance and Emissions Characteristics of a GDI Spark-Ignition Engine. Fuel 256, 115910. doi:10.1016/j.fuel.2019.115910

Li, Y., Wang, S., Duan, X., Liu, S., Liu, J., and Hu, S. (2021). Multi-objective Energy Management for Atkinson Cycle Engine and Series Hybrid Electric Vehicle Based on Evolutionary NSGA-II Algorithm Using Digital Twins. Energ. Convers. Manage. 230, 113788. doi:10.1016/j.enconman.2020.113788

Li, X., Sun, Z., Yang, S., Wang, H., and Nour, M. (2021). Flash Boiling Combustion of Isomeric Butanol and Gasoline Surrogate Blends Using Constant Volume spray Chamber and GDI Optical Engine. Fuel 286, 119328. doi:10.1016/j.fuel.2020.119328

Lin, X., Feng, Q., Mo, L., and Li, H. (2019). Optimal Adaptation Equivalent Factor of Energy Management Strategy for Plug-In CVT HEV. Proc. Inst. Mech. Eng. D: J. Automobile Eng. 233 (4), 877-889. doi:10.1177/0954407018755612

Lin, X., and Li, H. (2019). Adaptive Control Strategy Extracted from Dynamic Programming and Combined with Driving Pattern Recognition for SPHEB. Int.J Automot. Technol. 20 (5), 1009-1022. doi:10.1007/s12239019-0095-7

Lin, X., Wang, Z., and Wu, J. (2021). Energy Management Strategy Based on Velocity Prediction Using Back Propagation Neural Network for a Plug-in Fuel Cell Electric Vehicle. Int. J. Energ. Res 45 (2), 2629-2643. doi:10.1002/er.5956

Liu, A., Garcia, C. E., Sewerin, F., Williams, B. A. O., and Rigopoulos, S. (2020). Population Balance Modelling and Laser Diagnostic Validation of Soot Particle Evolution in Laminar Ethylene Diffusion Flames. Combustion and Flame 221, 384-400. doi:10.1016/j.combustflame.2020.06.036

Liu, A., and Rigopoulos, S. (2019). A Conservative Method for Numerical Solution of the Population Balance Equation, and Application to Soot Formation. Combustion and Flame 205, 506-521. doi:10.1016/j.combustflame.2019.04.019

Liu, H., Wang, X., Zhang, D., Dong, F., Liu, X., Yang, Y., et al. (2019). Investigation on Blending Effects of Gasoline Fuel with N-Butanol, DMF, and Ethanol on the Fuel Consumption and Harmful Emissions in a GDI Vehicle. Energies 12 (10), 1845. doi: $10.3390 /$ en 12101845

Liu, J., and Dumitrescu, C. E. (2020a). Limitations of Natural Gas Lean Burn Spark Ignition Engines Derived from Compression Ignition Engines. J. Energ. Resour. Techn. 142 (12), 122308. doi:10.1115/1.4047404

Liu, J., and Dumitrescu, C. E. (2020b). Improved Thermodynamic Model for Lean Natural Gas Spark Ignition in a Diesel Engine Using a Triple Wiebe Function. J. Energ. Resour. Techn. 142 (6), 062303. doi:10.1115/1.4045534

Liu, J., and Dumitrescu, C. E. (2018). 3D CFD Simulation of a CI Engine Converted to SI Natural Gas Operation Using the G-Equation. Fuel 232, 833-844. doi:10. 1016/j.fuel.2018.05.159

Liu, J., and Dumitrescu, C. E. (2019). Analysis of Two-Stage Natural-Gas Lean Combustion inside a Diesel Geometry. Appl. Therm. Eng. 160, 114116. doi:10. 1016/j.applthermaleng.2019.114116

Liu, J., and Wang, H. (2022). Machine Learning Assisted Modeling of Mixing Timescale for LES/PDF of High-Karlovitz Turbulent Premixed Combustion. Combustion and Flame 238, 111895. doi:10.1016/j.combustflame.2021.111895

Liu, A., Luo, K. H., Rigopoulos, S., and Jones, W. (2021). Effects of the Electric Field on Soot Formation in Combustion: A Coupled Charged Particle PBE-CFD Framework. Combustion and Flame, 111796. doi:10.1016/j.combustflame.2021.111796

Liu, J., Huang, Q., Ulishney, C., and Dumitrescu, C. E. (2021). Machine Learning Assisted Prediction of Exhaust Gas Temperature of a Heavy-Duty Natural Gas Spark Ignition Engine. Appl. Energ. 300, 117413. doi:10.1016/j.apenergy.2021.117413

Liu, J., Ulishney, C. J., and Dumitrescu, C. E. (2021). Experimental Investigation of a Heavy-Duty Natural Gas Engine Performance Operated at Stoichiometric and Lean Operations. Energ. Convers. Manage. 243, 114401. doi:10.1016/j. enconman.2021.114401

Liu, Z., Zhang, Y., Fu, J., and Liu, J. (2021). "Three-dimensional Fluid Dynamics Modeling of a 6V150 Diesel Engine," in ASME 2021 International Mechanical Engineering Congress and Exposition (American Society of Mechanical Engineers), IMECE2021-67711.

Lucchini, T., D’Errico, G., Onorati, A., Bonandrini, G., Venturoli, L., and Di Gioia, R. (2012). Development of a CFD Approach to Model Fuel-Air Mixing in 
Gasoline Direct-Injection Engines. SAE Technical Paper. doi:10.4271/2012-010146

Ma, J., Zhao, H., Freeland, P., Hawley, M., and Xia, J. (2014). Numerical Analysis of a Downsized 2-stroke Uniflow Engine. SAE Int. J. Engines 7 (4), 2035-2044. doi:10.4271/2014-01-9051

Papageorgakis, G., and Assanis, D. N. (1998). Optimizing Gaseous Fuel-Air Mixing in Direct Injection Engines Using an RNG Based K- $\varepsilon$ Model. SAE Trans., 82-107. doi:10.4271/980135

Potenza, M., Milanese, M., and de Risi, A. (2019). Effect of Injection Strategies on Particulate Matter Structures of a Turbocharged GDI Engine. Fuel 237, 413-428. doi:10.1016/j.fuel.2018.09.130

Shi, Z., Lee, C.-f., Wu, H., Li, H., Wu, Y., Zhang, L., et al. (2020). Effect of Injection Pressure on the Impinging spray and Ignition Characteristics of the HeavyDuty Diesel Engine under Low-Temperature Conditions. Appl. Energ. 262, 114552. doi:10.1016/j.apenergy.2020.114552

Shi, Z., Lee, C.-f., Wu, H., Wu, Y., Zhang, L., and Liu, F. (2019). Optical Diagnostics of Low-Temperature Ignition and Combustion Characteristics of Diesel/ kerosene Blends under Cold-Start Conditions. Appl. Energ. 251, 113307. doi:10.1016/j.apenergy.2019.113307

Shi, Z., Zhang, H., Wu, H., and Xu, Y. (2018). Ignition Properties of Lean DME/H2 Mixtures at Low Temperatures and Elevated Pressures. Fuel 226, 545-554. doi:10.1016/j.fuel.2018.04.043

Stocchi, I., Liu, J., Dumitrescu, C. E., Battistoni, M., and Grimaldi, C. N. (2019). Effect of Piston Crevices on the Numerical Simulation of a Heavy-Duty Diesel Engine Retrofitted to Natural-Gas Spark-Ignition Operation. J. Energ. Resour. Technol. 141 (11), 112204. doi:10.1115/1.4043709

Sun, Z., Cui, M., Ye, C., Yang, S., Li, X., Hung, D., et al. (2021). Split Injection Flash Boiling Spray for High Efficiency and Low Emissions in a GDI Engine under Lean Combustion Condition. Proc. Combustion Inst. 38 (4), 5769-5779. doi:10. 1016/j.proci.2020.05.037

Verma, I., Bish, E., Kuntz, M., Meeks, E., Puduppakkam, K., Naik, C., et al. (2016). CFD Modeling of Spark Ignited Gasoline Engines-Part 2: Modeling the Engine in Direct Injection Mode along with spray Validation. SAE Technical Paper.

Verma, I., Bish, E., Kuntz, M., Meeks, E., Puduppakkam, K., Naik, C., et al. (2016). CFD Modeling of Spark Ignited Gasoline Engines-Part 1: Modeling the Engine under Motored and Premixed-Charge Combustion Mode. SAE Technical Paper.

Wang, J., and Shuai, S. (2011). Principles of Automobile Engines. [M] Beijing: Tsinghua University Press.

Wang, S., Luo, K., and Fan, J. (2020). CFD-DEM Coupled with Thermochemical Sub-models for Biomass Gasification: Validation and Sensitivity Analysis. Chem. Eng. Sci. 217, 115550. doi:10.1016/j.ces.2020.115550

Wang, S., and Shen, Y. (2020). CFD-DEM Study of Biomass Gasification in a Fluidized Bed Reactor: Effects of Key Operating Parameters. Renew. Energ. 159, 1146-1164. doi:10.1016/j.renene.2020.06.001

Wang, S., and Shen, Y. (2021a). Particle-scale Modelling of Raceway Dynamics in a Blast Furnace Using a Smoothing Method. Powder Techn. 389, 189-203. doi:10. 1016/j.powtec.2021.05.020

Wang, S., and Shen, Y. (2021b). Particle-scale Study of Heat and Mass Transfer in a Bubbling Fluidised Bed. Chem. Eng. Sci. 240, 116655. doi:10.1016/j.ces.2021. 116655

Wang, S., and Shen, Y. (2021c). CFD-DEM Modelling of Raceway Dynamics and Coke Combustion in an Ironmaking Blast Furnace. Fuel 302, 121167. doi:10. 1016/j.fuel.2021.121167

Wen, M., Zhang, C., Yue, Z., Liu, X., Yang, Y., Dong, F., et al. (2020). Effects of Gasoline Octane Number on Fuel Consumption and Emissions in Two Vehicles Equipped with GDI and PFI Spark-Ignition Engine. J. Energ. Eng. 146 (6), 04020069. doi:10.1061/(asce)ey.1943-7897.0000722
Xu, Z., Ji, F., Ding, S., Zhao, Y., Zhang, X., Zhou, Y., et al. (2020a). High-altitude Performance and Improvement Methods of Poppet Valves 2-stroke Aircraft Diesel Engine. Appl. Energ. 276, 115471. doi:10.1016/j.apenergy.2020.115471

Xu, Z., Ji, F., Ding, S., Zhao, Y., Wang, Y., Zhang, Q., et al. (2020b). Simulation and Experimental Investigation of Swirl-Loop Scavenging in Two-Stroke Diesel Engine with Two Poppet Valves. Int. J. Engine Res., 1468087420916083. doi:10. 1177/1468087420916083

Xu, Z., Ji, F., Ding, S., Zhao, Y., Zhou, Y., Zhang, Q., et al. (2021). Digital TwinDriven Optimization of Gas Exchange System of 2-stroke Heavy Fuel Aircraft Engine. J. Manufacturing Syst. 58, 132-145. doi:10.1016/j.jmsy.2020.08.002

Yang, R., Sun, X., Liu, Z., Zhang, Y., and Fu, J. (2021). A Numerical Analysis of the Effects of Equivalence Ratio Measurement Accuracy on the Engine Efficiency and Emissions at Varied Compression Ratios. Processes 9 (8), 1413. doi:10. 3390/pr9081413

Yu, H., Duan, S., and Sun, P. (2015). Comparative Analysis between Natural Gas/ diesel (Dual Fuel) and Pure Diesel on the marine Diesel Engine. J. Eng. Res. 3 (4), 1-5. doi:10.7603/s40632-015-0037-0

Yu, H., Duan, S., and Sun, P. (2017). Numerical Simulation of Combustion Progress on Dual Fuel Engines with Different Turbulence Models. J. Eng. Res. 5 (4).

Yu, H., Wang, W., Sheng, D., Li, H., and Duan, S. (2022). Performance of Combustion Process on marine Low Speed Two-Stroke Dual Fuel Engine at Different Fuel Conditions: Full Diesel/diesel Ignited Natural Gas. Fuel 310, 122370. doi:10.1016/j.fuel.2021.122370

Zeng, K., Huang, Z., Liu, B., Liu, L., Jiang, D., Ren, Y., et al. (2006). Combustion Characteristics of a Direct-Injection Natural Gas Engine under Various Fuel Injection Timings. Appl. Therm. Eng. 26 (8-9), 806-813. doi:10.1016/j. applthermaleng.2005.10.011

Zhang, Y., Zhao, H., Ojapah, M., and Cairns, A. (2012). Effects of Injection Timing on CAI Operation in a 2/4-stroke Switchable GDI Engine. SAE Int. J. Engines 5 (2), 67-75. doi:10.4271/2011-01-1773

Zhao, F., Lai, M.-C., and Harrington, D. L. (1999). Automotive Spark-Ignited Direct-Injection Gasoline Engines. Prog. Energ. combustion Sci. 25 (5), 437-562. doi:10.1016/s0360-1285(99)00004-0

Zheng, X. U., Fenzhu, J. I., Shuiting, D. I., Yunhai, Z. H., Yu, Z. H., Zhang, Q., et al. (2021). Effect of Scavenge Port Angles on Flow Distribution and Performance of Swirl-Loop Scavenging in 2-stroke Aircraft Diesel Engine. Chin. J. Aeronautics 34 (3), 105-117. doi:10.1016/j.cja.2020.07.015

Zhu, Y. X. (2019). Research on the Effect of Fuel Temperature on Combustion and Emission of GDI Engine [D]. Jilin University.

Conflict of Interest: The authors declare that the research was conducted in the absence of any commercial or financial relationships that could be construed as a potential conflict of interest.

Publisher's Note: All claims expressed in this article are solely those of the authors and do not necessarily represent those of their affiliated organizations, or those of the publisher, the editors and the reviewers. Any product that may be evaluated in this article, or claim that may be made by its manufacturer, is not guaranteed or endorsed by the publisher.

Copyright $\odot 2022$ Zhang, Yang, Yan, Li, Fu and Liu. This is an open-access article distributed under the terms of the Creative Commons Attribution License (CC BY). The use, distribution or reproduction in other forums is permitted, provided the original author(s) and the copyright owner(s) are credited and that the original publication in this journal is cited, in accordance with accepted academic practice. No use, distribution or reproduction is permitted which does not comply with these terms. 